\title{
Biogas Upgrading by Pressure Swing Adsorption
}

\author{
Carlos A. Grande \\ SINTEF Materials and Chemistry, Oslo \\ Norway
}

\section{Introduction}

Biogas is a raw gaseous stream produced by anaerobic decomposition of organic matter. The main component of biogas is methane, reason why this stream is considered to be a renewable source of energy and fuel. The most positive aspects of biogas rely on its worldwide decentralized production and on the environmental benefits of avoiding methane emissions to atmosphere while using bio-methane it to replace fossil fuels.

In order to use the energy obtained in biogas, its production should be controlled. The production of biogas from organic matter is a complex process involving many different bacterial groups. In a simple way, the entire biogas conversion from organic matter can be divided into four steps (Gavala et al., 2003; Demirbas et al., 2011):

1. Hydrolisis: complex organic molecules are hydrolyzed into smaller units (sugars, amino-acids, alcohols, fatty acids, etc.

2. Acidogenese: acidogenic bacteria further break down the molecules into volatile fatty acids, $\mathrm{NH}_{3}, \mathrm{H}_{2} \mathrm{~S}$ and $\mathrm{H}_{2}$.

3. Acetanogese: the acetanogens transform the molecules into $\mathrm{CO}_{2}, \mathrm{H}_{2}$ and mainly acetic acid.

4. Metanogese: at the end of the process, the methanogenic archaea transform the $\mathrm{H}_{2}$ and acetic acid molecules into a mixture of $\mathrm{CO}_{2}, \mathrm{CH}_{4}$ and water.

These production steps can be controlled in reactors (digesters) or are naturally occurring in landfills that can be optimized for collection of biogas (see www.epa.gov/lmop). The digesters can operate in mesophilic and thermophilic modes, which means that the biogas is generated at 293-313 K and 323-333 K, respectively (Gavala et al., 2003). Biogas generation in landfills mainly operates in psychrophilic conditions (285-290 K) (Monteiro et al., 2011). Biogas main constituents are methane, carbon dioxide, sulphur compounds $\left(\mathrm{H}_{2} \mathrm{~S}\right.$, siloxanes), water and minor contaminants $\left(\mathrm{O}_{2}, \mathrm{~N}_{2}\right.$, ammonia, chlorine, fluorines, etc) (Wellinger, 2009; Pettersson and Wellinger, 2009, www.epa.gov/lmop). The final composition of biogas is variable and strongly depends on the source of organic matter (Pettersson and Wellinger, 2009). Major sources of biogas production are landfills, waste-water treatment plants, manure fermentation and fermentation of energy crops. The composition of the biogas obtained from these sources is given in Table 1. For comparison, the composition and properties of natural gas are included in Table 1 . The methane content vary strongly due to the different kind of molecules processed: i.e, fat has a much higher bio-methane yield than carbohydrates. The biogas yield of cereal residues is also high (around $200 \mathrm{~m}^{3} \mathrm{CH}_{4}$ /ton) 
(Pettersson and Wellinger, 2009), representing an interesting opportunity for fermentation in farms around the world.

Since the content of methane in biogas streams is higher than $50 \%$, its emissions to atmosphere result in a waste of an efficient hydrocarbon which also has a greenhouse warming potential 23 times higher than $\mathrm{CO}_{2}$. For this reason, adequate collection and utilization of the bio-methane contained in biogas avoid important emissions of methane to atmosphere and also transforms this stream in a valuable source of renewable energy. The bio-methane can be directly burned and converted to electric power. In fact, biogas utilization for production of electric energy is increasing worldwide.

\begin{tabular}{|l|l|l|l|}
\hline Gas & Biogas & Landfill gas & Natural gas \\
\hline $\mathrm{CH}_{4}(\%)$ & $90-70$ & $65-65$ & 90 \\
\hline $\mathrm{Hydrocarbons}(\%)$ & 0 & 0 & 9 \\
\hline $\mathrm{H}_{2}(\%)$ & 0 & $0-3$ & 0 \\
\hline $\mathrm{CO}_{2}(\%)$ & $30-40$ & $15-50$ & 1 \\
\hline $\mathrm{N}_{2}(\%)$ & $\sim 0.2$ & $5-40$ & 0.3 \\
\hline $\mathrm{O}_{2}(\%)$ & 0 & $0-5$ & 0 \\
\hline $\mathrm{H}_{2} \mathrm{~S}(\mathrm{ppm})$ & $0-4000$ & $0-100$ & 3 \\
\hline $\mathrm{NH}_{3}(\mathrm{ppm})$ & 100 & 5 & 0 \\
\hline Heating value, $\mathrm{kWh} / \mathrm{Nm}^{3}$ & 6.5 & 4.4 & 11.0 \\
\hline
\end{tabular}

Table 1. Average composition and properties of natural gas and different biogas streams.

An alternative application of biogas is its upgrading to obtain purified bio-methane that can be either injected in the natural gas grid or be directly used as vehicle fuel. The purification of biogas involves several steps: removal of impurities (sulphur compounds mainly), water removal and the upgrading process which consist in bulk removal of $\mathrm{CO}_{2}$. Normally the removal of sulphur compounds is the first step in biogas cleaning. The order of separating $\mathrm{H}_{2} \mathrm{O}$ and $\mathrm{CO}_{2}$ depends on the specific technology employed for upgrading. The bio-methane obtained as product should hold certain purity and the maximum quantity of $\mathrm{CO}_{2}$ allowed is between $2-4 \%$ depending on the legislation of each country. From all the purification steps, the bulk removal of $\mathrm{CO}_{2}$ is the most expensive one and is the one that will be considered in this Chapter.

\section{Technologies for removal of carbon dioxide from biogas}

The upgrading of biogas $\left(\mathrm{CO}_{2}\right.$ removal) takes between $3-6 \%$ of the energy of biogas and may cost up to $€ 10 / \mathrm{GJ}$ in small streams. Nevertheless, it has been shown that transporting upgraded biogas may result in better overall energy efficiency than converting it to electricity on-site (Pettersson and Wellinger, 2009). There are several commercial technologies to remove $\mathrm{CO}_{2}$ from biogas streams. So far, there is not a clear best-technology and the cost of upgrading of all technologies is quite similar decreasing only with plant capacity (Wellinger, 2009). The selection of the proper technology to upgrade biogas depends on gas flowrate, value of utilities, legislation, etc.

The most important biogas upgrading techniques are scrubbing with water or other physical solvent, chemical scrubbing, membranes and Pressure Swing Adsorption (PSA). In this Chapter, only a small description of the phenomena underlying these processes will be given. The main purpose of this Chapter is to explain in detail the PSA technique for biogas 
upgrading, some examples of application and also some new trends in research that can be employed to reduce the size of PSA processes to produce bio-methane economically in small scale (farm-oriented).

\subsection{Water scrubbing}

Carbon dioxide is more soluble in water than methane. This phenomenon is employed to remove $\mathrm{CO}_{2}$ from biogas in water scrubbing technologies. Biogas is fed to a column where it is "washed" with counter-current water that is sprayed from the top of the column. The column is normally filled with some material to enhance the interface area promoting $\mathrm{CO}_{2}$ absorption. The $\mathrm{CO}_{2}$ is dissolved in the water that is then pumped to a "regeneration column" where $\mathrm{CO}_{2}$ is released. The regeneration of the water scrubbing process can be carried out at higher temperatures or at lower pressures. In this technology, $\mathrm{H}_{2} \mathrm{~S}$ is removed with $\mathrm{CO}_{2}$. Also the purified $\mathrm{CH}_{4}$ stream (with purity up to $98 \%$ ) should be dried after leaving the scrubber.

The solubility of $\mathrm{CO}_{2}$ in water strongly increases at lower temperatures. In order to reduce pumping energy, the water should be available at low temperatures. In fact, this technique is been employed in several countries with cold weather (Sweden, Switzerland, Germany, Austria, etc). Cooling down water may still be efficient for large facilities, but not for small applications.

Nowadays, water scrubbing is the most employed technique for upgrading biogas. Plants with processing capabilities from 80 to $10000 \mathrm{~m}^{3} /$ hour are in operation. Main technology developers in this area are: Malmberg (www.malmberg.se), Flotech Inc. (www.flotech.com), Rosroca (www.rosroca.de), DMT (www.dirkse-milieutechniek.com), etc. In some of these webpages there is a video which actually explain graphically in detail how the process works.

\subsection{Chemical scrubbing}

In a similar manner to water scrubbing, it is possible to use other chemicals to absorb $\mathrm{CO}_{2}$. The technology is also composed by $\underline{\mathrm{AN}}$ absorption tower where the chemical solvent is flushed to selectively absorb $\mathrm{CO}_{2}$. The saturated absorbent is then heated in a regeneration tower, releasing $\mathrm{CO}_{2}$. This technology is widely employed to clean large facilities in the natural gas industry. The selection of the solvent for this process is quite important since the "energy" of $\mathrm{CO}_{2}$ absorption dictates the final consumption of energy of the system. Chemicals which strongly absorb $\mathrm{CO}_{2}$ (like amines) are more suitable to upgrade methane with relatively low content of $\mathrm{CO}_{2}$ to a very high purity. This process may have higher energetic penalties since the $\mathrm{CO}_{2}$ removal in biogas is a bulk removal process. On the other side, for bulk $\mathrm{CO}_{2}$ removal to obtain a $\mathrm{CH}_{4}$ purity in the range $97-98 \%$, physical solvents consume less energy being more energy efficient. Different examples of physical absorbents are: methanol, Selexol, Rectisol, Genosorb, Morphysorb, etc. Plants able to process biogas flowrates of 55 to $13000 \mathrm{~m}^{3}$ /hour are in operation. Several companies provide this technology(Pettersson and Wellinger, 2009).

\subsection{Membranes}

The use of membranes for gas cleaning is a well established technology in chemical industries. The membrane is a porous material that let some gases permeate through its structure. Employing an adequate material, it is possible to have selectivity between the 
gases of the mixture to be separated. For this particular application, two different streams are obtained: a permeate gas (mainly $\mathrm{CO}_{2}$, water and ammonia) and the retentate (concentrated $\mathrm{CH}_{4}$ ). The most commonly employed materials are hollow fibres made of different polymers. Several companies provide this technology, being Air Liquide the largest company in this area (Air Liquide, 2011). In their process, the biogas is compressed to 16 bars and then routed to a two-stage membrane process where methane with purity higher than $90 \%$ can be obtained. To upgrade $\mathrm{CH}_{4}$ to a higher purity, a PSA process can be used in series.

\subsection{Pressure Swing Adsorption (PSA)}

Pressure Swing Adsorption (PSA) is the second most employed techniques for biogas upgrading. Several companies develop and commercialize this technology: Carbotech (www.carbotech.de), Acrona (www.acrona-systems.com), Cirmac (www.cirmac.com), Gasrec (www.gasrec.co.uk), Xebec Inc (www.xebecinc.com), Guild Associates (www.moleculargate.com), etc. Small scale plants (flowrate of $10 \mathrm{~m}^{3} /$ hour of biogas) are in operation, but this technology is also available for much higher flowrates $\left(10000 \mathrm{~m}^{3} /\right.$ hour of biogas).

In PSA processes, biogas is compressed to a pressure between 4-10 bar and is fed to a vessel (column) where is putted in contact with a material (adsorbent) that will selectively retain $\mathrm{CO}_{2}$. The adsorbent is a porous solid, normally with high surface area. Most of the adsorbents employed in the commercial processes are carbon molecular sieves (CMS) but also activated carbons, zeolites and other materials (titanosilicates) are employed. The purified $\mathrm{CH}_{4}$ is recovered at the top of the column with a very small pressure drop. After certain time, the adsorbent is saturated with $\mathrm{CO}_{2}$, and the column needs to be regenerated by reducing the pressure (normally to vacuum for biogas upgrading). The adsorption of $\mathrm{H}_{2} \mathrm{~S}$ is normally irreversible in the adsorbents and thus a process to eliminate this gas should be placed before the PSA. Alternatively, depending on the choice of the adsorbent, the humidity contained in the biogas stream can be removed together with $\mathrm{CO}_{2}$ in the same unit. Multi-column arrays are employed to emulate a continuous process. For small applications subjected to discontinuities, a single column with storage tanks may be used. One of the most important properties of the PSA process is that is can be adapted to biogas upgrading in any part of the world since it does not depend on the availability of cold or hot sources. A detailed explanation of this process follows.

\section{Principles of Pressure Swing Adsorption for biogas upgrading}

In a PSA unit for biogas upgrading, an adsorbent material is subjected to pressure changes to selectively adsorb and desorb $\mathrm{CO}_{2}$. Adsorption is an exothermic spontaneous process and the loading of $\mathrm{CO}_{2}$ in the adsorbent depends specifically on the properties of the material employed (surface area and composition, pore size, etc). Once the material is specified, then its regeneration should be realized. Note that since the material is continuously used and regenerated, there comes a point where the process achieves a "cyclic steady state" (CSS). The largest part of engineering a PSA process rely in designing a regeneration protocol for the adsorbent able to spent small amount of energy (reduce energetic penalty) and do it in the fastest way possible (increase productivity).

The operational principle of the PSA process can be observed in Figure 1 where two generic $\mathrm{CO}_{2}$ isotherms (representing two different materials) are shown. In both materials, the 
adsorbent may take $\mathrm{CO}_{2}$ up to the loading established by its partial pressure in the feed step ( $\mathrm{P}_{\text {feed }}$ ) which is $\mathrm{q}_{\text {feed,1 }}$ and $\mathrm{q}_{\text {feed,2 }}$ for adsorbents 1 and 2, respectively. After the adsorbent is saturated, it is regenerated to a lower pressure, $\mathrm{P}_{\text {reg, }}$, where the loading of $\mathrm{CO}_{2}$ decreases to $\mathrm{q}_{\mathrm{reg}, 1}$ and $\mathrm{q}_{\mathrm{reg}, 2}$. The material 1 has a higher $\mathrm{CO}_{2}$ capacity than material 2 for the entire pressure range. However, the difference in loading between $\mathrm{q}_{\text {feed }}$ and $\mathrm{q}_{\mathrm{reg}}(\Delta \mathrm{q})$ is higher for material 2, indicating that the "cyclic capacity" will be better for this material. In fact, the conclusion from this image is that it is important to know the shape of the isotherm in order to design the PSA process. Also, ideally for PSA applications, linear or mild non-linear isotherms are better than very steep isotherms with high loading. Furthermore, when the isotherms are steep, it is more difficult to regenerate the adsorbent since the energy required to desorb $\mathrm{CO}_{2}$ is higher. From Figure 1, it is possible to see that the selection of the regeneration pressure has also an important effect in the cyclic operation of the PSA process. For this reason, in the next sections, the properties of the adsorbents and the cycles used for adsorbent regeneration in PSA for biogas upgrading will be discussed.

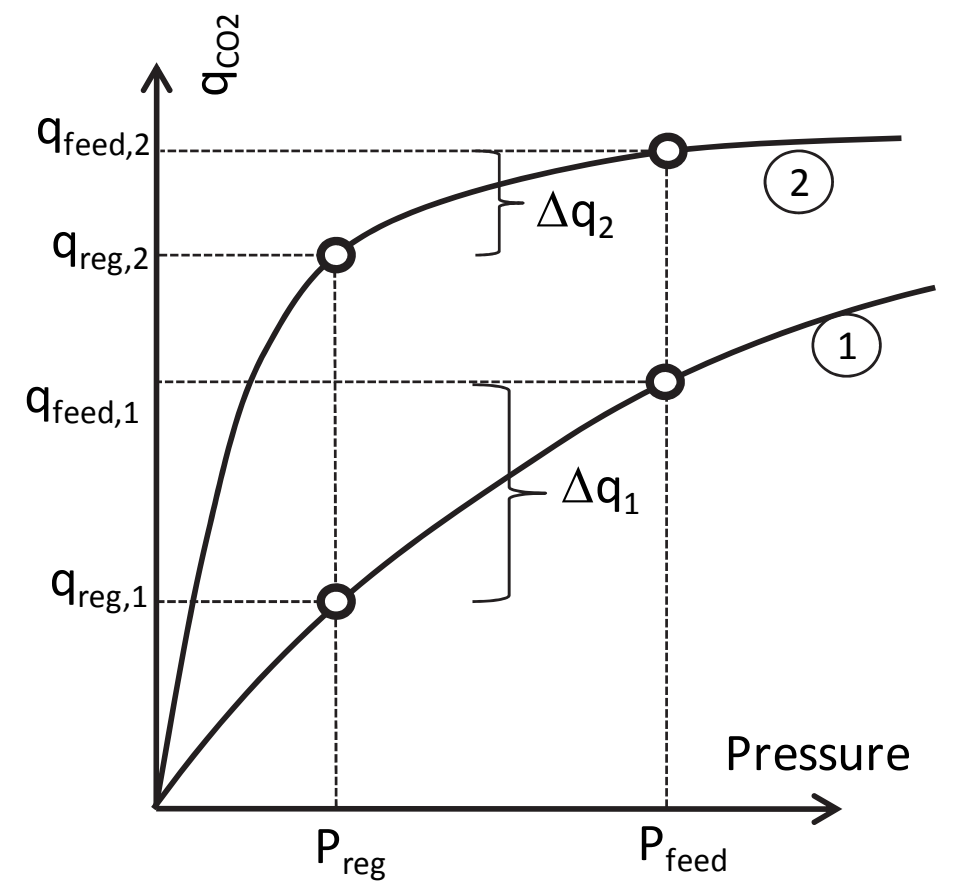

Fig. 1. Generic $\mathrm{CO}_{2}$ isotherms for two different materials (1) and (2) indicating partial pressure of $\mathrm{CO}_{2}$ in feed step and regeneration (low) pressure.

\subsection{Adsorbents}

It can be said that the adsorbent material is the "heart" of the PSA unit. All the properties of the cycle (operating conditions and operating mode) depend on the initial choice of the adsorbent. As mentioned before, several materials can be employed in PSA technology. The material selected should at least satisfy one of two criteria: 
i. have a higher selectivity to $\mathrm{CO}_{2}$ : this gas should be more "attached" to the surface of the material than $\mathrm{CH}_{4}$; in most solids $\mathrm{CO}_{2}$ can create stronger bonds with surface groups than $\mathrm{CH}_{4}$. This kind of materials will be termed as equilibrium-based adsorbents since its main selectivity is due to differences of interaction forces between $\mathrm{CO}_{2}$ and $\mathrm{CH}_{4}$ with and the surface.

ii. the pores of the adsorbent can be adjusted in such a way that $\mathrm{CO}_{2}$ (kinetic diameter of $3.4 \AA$ ) can easily penetrate into their structure while larger $\mathrm{CH}_{4}$ molecules (kinetic diameter of $3.8 \AA$ ) have size limitations to diffuse through them. These materials will be termed as kinetic adsorbents since its main selectivity is due to diffusion constrains.

Carbon molecular sieves are one of the most employed materials for biogas upgrading. Adsorption equilibrium isotherms of $\mathrm{CO}_{2}$ and $\mathrm{CH}_{4}$ in CMS-3K (Takeda Corp., Japan) are shown in Figure 2 (Cavenati et al., 2005). This material has a clear selectivity towards $\mathrm{CO}_{2}$, but the most important property in CMS-3K is not its equilibrium selectivity, but the kinetic selectivity. In this material, $\mathrm{CO}_{2}$ adsorbs much faster than $\mathrm{CH}_{4}$ : adsorption equilibrium of $\mathrm{CH}_{4}$ is achieved only after two days of solid-gas contact. In fact, the pore mouth of CMS-3K is narrowed to dimension closer to the kinetic diameter of $\mathrm{CH}_{4}$ creating a specific resistance (mass transfer in the micropore mouth) (Srinivasan et al., 1995) that can be seen in the initial moments of $\mathrm{CH}_{4}$ uptake in Figure 2 (b). Another material that also presents strong resistance to $\mathrm{CH}_{4}$ diffusion is ETS-4 (titanosilicate-4) modified with alkali-earth metals (Kuznicki, 1990; Marathe et al., 2004; Cavenati et al., 2009). In this material, the pore diameter can be tuned with different heating temperatures resulting in a "molecular gate" effect that actually named the process commercialized by Guild Associates Inc. (USA).

Other normally employed adsorbents are activated carbons and zeolites. In these materials, the diffusion of both gases can be very fast and actually what is exploited is the difference between loadings of $\mathrm{CO}_{2}$ and $\mathrm{CH}_{4}$. An example of these equilibrium-based materials is given in Figure 3, where adsorption equilibrium of $\mathrm{CO}_{2}$ and $\mathrm{CH}_{4}$ on zeolite $13 \mathrm{X}$ (CECA, France) is shown (Cavenati et al., 2004). Note that the loading of $\mathrm{CO}_{2}$ is much higher than the loading of $\mathrm{CH}_{4}$ at given $\mathrm{P}, \mathrm{T}$ conditions. Furthermore, recasting the conclusions taken from Figure 1, the cyclic $\mathrm{CO}_{2}$ capacity at lower temperatures is smaller than at higher temperatures, which means that if zeolite $13 \mathrm{X}$ is employed at $323 \mathrm{~K}$, it will be easier to regenerate than at $298 \mathrm{~K}$.
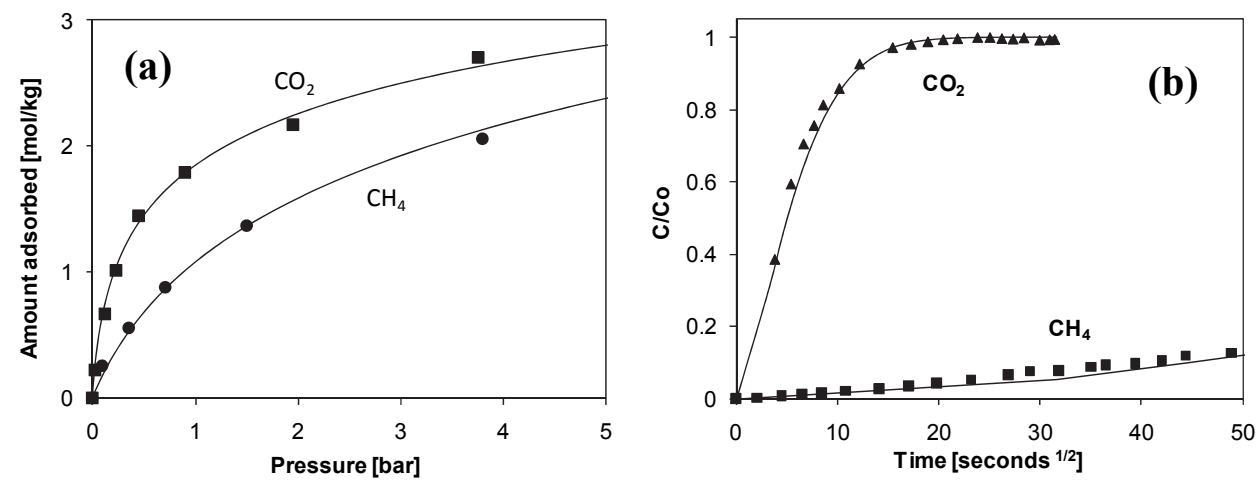

Fig. 2. Adsorption of $\mathrm{CO}_{2}$ and $\mathrm{CH}_{4}$ in carbon molecular sieve 3K (Takeda Corp, Japan) at 298 K: (a) adsorption equilibrium; (b) uptake rate curves (data from Cavenati et al., 2005). 
Another topic that is important for the selection of materials for the PSA process for biogas upgrading, is the presence of contaminants. Apart from $\mathrm{CH}_{4}$ and $\mathrm{CO}_{2}$, other gases present in biogas are $\mathrm{H}_{2} \mathrm{~S}$ and $\mathrm{H}_{2} \mathrm{O}$. In almost all adsorbents, $\mathrm{H}_{2} \mathrm{~S}$ is irreversibly adsorbed, reason why it has to be removed before the PSA process. When carbonaceous materials are employed it is possible to remove $\mathrm{H}_{2} \mathrm{O}$ in the same vessel as $\mathrm{CO}_{2}$. However, that is not possible using zeolites since water adsorption is also very steep, resulting in a very difficult desorption.
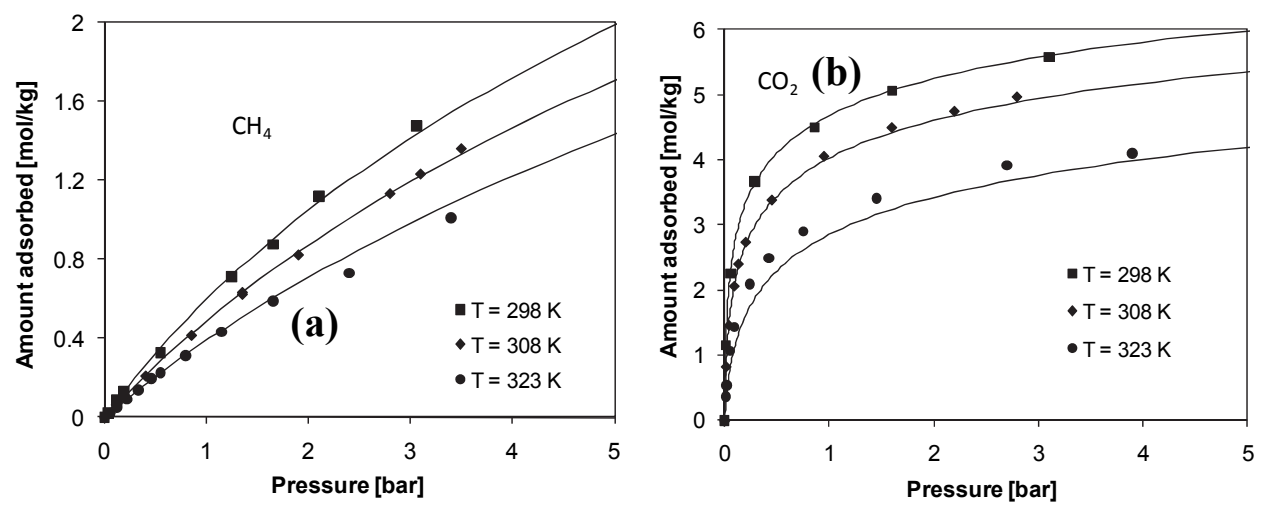

Fig. 3. Adsorption equilibrium of $\mathrm{CO}_{2}$ (a) and $\mathrm{CH}_{4}$ (b) on zeolite $13 \mathrm{X}$ at 298,308 and $323 \mathrm{~K}$ (Data from Cavenati et al., 2004).

\subsection{Packed-bed performance}

Adsorption is a spontaneous process and when the gas is putted in contact with the adsorbent, a new equilibrium state will be established, depending on the partial pressure of each of the gases and on the total temperature of the system. After achieving such equilibrium, no more adsorption takes place and the adsorbent should be regenerated. For this reason, a PSA column should be regenerated periodically to be able to absorb $\mathrm{CO}_{2}$ in different cycles. In order to keep constant feed processing, more than one column are employed in parallel: when biogas is fed for selective removal of $\mathrm{CO}_{2}$, the other column(s) are being regenerated.

The operation of a PSA process for biogas upgrading can be explained by showing what happens when a mixture of $\mathrm{CH}_{4}-\mathrm{CO}_{2}$ is fed to a column filled with adsorbent. For simplicity, the column will be considered to be at the same pressure of the biogas stream and filled with an inert gas (helium). An example of such behaviour is normally termed as "breakthrough experiments". An example of a breakthrough curve of $\mathrm{CH}_{4}(55 \%)-\mathrm{CO}_{2}$ (45\%) mixture in CMS-3K is shown in Figure 4 (Cavenati et al., 2005). It can be observed that in the initial moments, methane molecules travel across the column filling the gas phase in the inter-particle space, but also in the intra-particle voids (macropores), replacing helium. Due to the very large resistance to diffuse into the micropores, $\mathrm{CH}_{4}$ adsorption is very difficult, reason why it breaks through the column very fast. On the other side, $\mathrm{CO}_{2}$ takes a very long time to break through the column since it is being continuously adsorbed. Note that before $\mathrm{CO}_{2}$ breakthrough, there is a period of time where only methane is obtained at the column product end. In Figure 4(b) also the temperature increase on the different positions of the column is shown. Note that in this experiment, temperature increase is due 
solely to $\mathrm{CO}_{2}$ adsorption. This experiment was carried out under non-isothermal and nonadiabatic conditions. In the case of larger adsorbers where adiabatic conditions can be found, temperature increase should be higher having a stronger negative impact in the adsorption of $\mathrm{CO}_{2}$ (faster breakthrough).

Another important thing that can be observed in Figure 4 is the dispersion of the $\mathrm{CO}_{2}$ curve. The perturbation in the feed stream was a step increase in $\mathrm{CH}_{4}$ and $\mathrm{CO}_{2}$ partial pressure and the breakthrough result indicates that the response to that input after passing through the column is quite spread. The shape of the adsorption breakthrough curves is associated to diverse factors:

1. Slope of the adsorption isotherms: comprise the concentration wave if isotherm is favourable (Langmuir Type) and dispersive if the adsorption equilibrium is unfavourable (desorption for Langmuir-type isotherms). No effect if the isotherm is linear,

2. Axial dispersion of the adsorption column: disperse the concentration wave,

3. Resistance to diffusion within the porous structure of the adsorbent: disperse the concentration wave.

4. Thermal effects: normally in gas separations the thermal wave travels at the same velocity as the concentration wave (Yang, 1987; Ruthven et al., 1994; Basmadjian, 1997) and its effect is to disperse the concentration wave. Thermal effects can control the shape of the breakthrough curve.
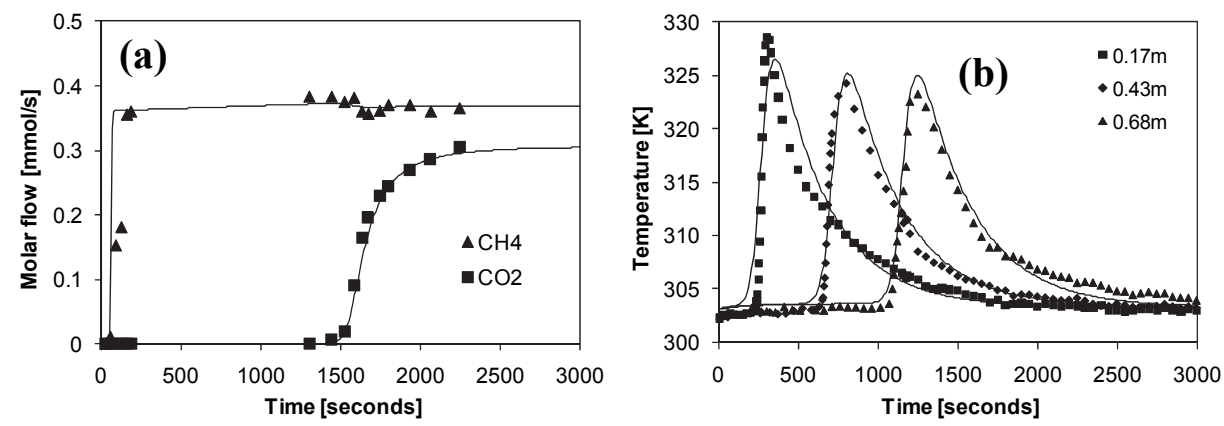

Fig. 4. Binary $\mathrm{CH}_{4}(55 \%)-\mathrm{CO}_{2}(45 \%)$ breakthrough curve experiment in fixed-bed filled with CMS-3K extrudates. Temperature: $303 \mathrm{~K}$; Pressure: 4 bar (data from Cavenati et al., 2004). (a): molar flow of $\mathrm{CH}_{4}$ and $\mathrm{CO}_{2}$; (b) temperature evolution in three different points of the column.

To compare the performance of different adsorbents, the thermal effects associated to adsorption of $\mathrm{CO}_{2}$ in zeolite 13X extrudates can be observed in Figure 5 where a breakthrough of $\mathrm{CO}_{2}$ was carried out (Cavenati et al., 2006). The experiment was conducted at $299 \mathrm{~K}$ and a total pressure of 3.2 bar. It can be observed that $\mathrm{CO}_{2}$ breaks through the bed quite sharply due to the strong non-linearity of the $\mathrm{CO}_{2}$ adsorption isotherm that tends to compress the concentration front. After the initial sharp breakthrough, the shape of the curve gets quite dispersed due to thermal effects. It can be seen in Figure 5(b) that the temperature increase in certain points of the column is quite high, reducing the loading of $\mathrm{CO}_{2}$ and making breakthrough quite faster than it should be if carried out at isothermal conditions. The opposite effect will take place in desorption of $\mathrm{CO}_{2}$ : the temperature in the 
bed will drop increasing the steepness of the adsorption isotherm, making desorption more unfavourable.
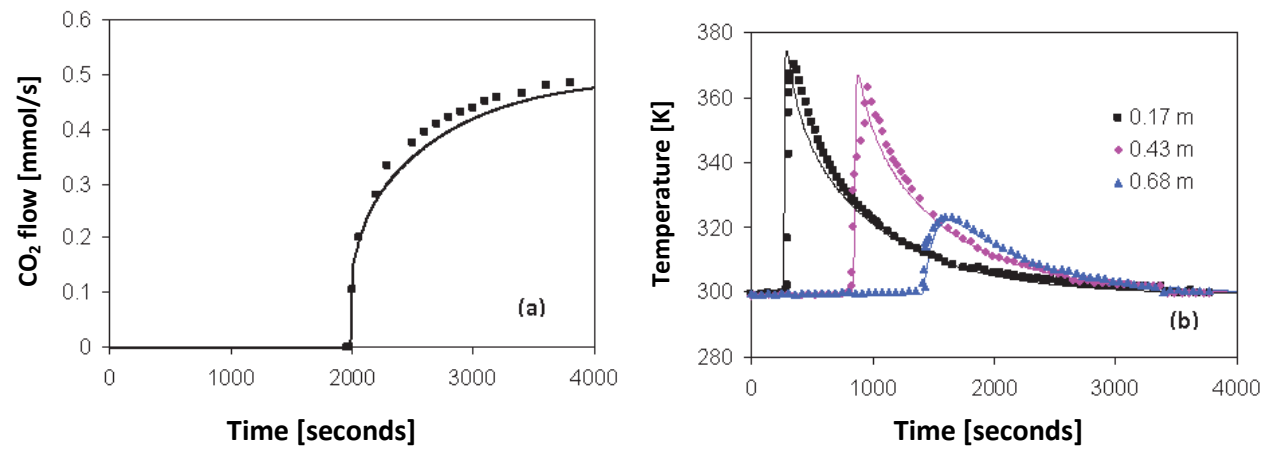

Fig. 5. Breakthrough curve of pure $\mathrm{CO}_{2}$ in fixed-bed filled with zeolite $13 \mathrm{X}$ extrudates. Temperature: 299 K; Pressure: 3.2 bar (data from Cavenati et al., 2006). (a): molar flow of $\mathrm{CO}_{2} ;(\mathrm{b})$ temperature evolution in three different points of the column.

Due to the thermal effects and the steepness of the $\mathrm{CO}_{2}$ isotherm on zeolite $13 \mathrm{X}$, it was concluded that using a similar PSA cycle, if the temperature of the biogas stream is close to ambient temperature, it is better to use the Carbon Molecular Sieve (CMS-3K) than zeolite 13X (Grande and Rodrigues, 2007).

The solid lines shown in Figures 4 and 5, represent the prediction of a mathematical model, based on pure gas adsorption equilibrium and kinetics (Cavenati et al., 2004; Cavenati et al., 2005). The resulting equations for the prediction of the fixed-bed behaviour are (Da Silva, 1999):

i. mass balances in the column, particle and micropores (crystals) of the adsorbent.

ii. Energy balances in the gas and solid phases and column wall

iii. Momentum balance (simplified to the Ergun equation)

iv. Multicomponent adsorption isotherm model.

Note that the mass, energy and momentum balances are partial differential equations linked by a (generally) non-linear equation (isotherm model). The mathematical model was tested under diverse adsorbents and operating conditions for $\mathrm{CH}_{4}-\mathrm{CO}_{2}$ separation as well as for other gas mixtures. The mathematical model employed is termed as "homogeneous model" since it considers mass and heat transfer in different phases using different equations. Heterogeneous models (single energy balance) and also more simplified mass transfer models can also be employed to predict column behaviour with good accuracy (Ruthven, 1984; Yang, 1987; Ruthven et al., 1994).

\subsection{Packed-bed regeneration: basic cycles}

Once that the adsorbent is selected to perform a given $\mathrm{CH}_{4}-\mathrm{CO}_{2}$ separation under specific operating conditions $\left(T, P, y_{\mathrm{CO} 2}\right)$, there are only few actions that can be taken to make the adsorption step more efficient (dealing with energy transfer, for example). When designing the upgrading PSA, the most important task is to make desorption efficiently.

The initial work reporting Pressure Swing Adsorption technology was signed by Charles W. Skarstrom in 1960 (Skarstrom, 1960). A similar cycle was developed by Guerin - Domine in 
1964 (Guerin and Domine, 1964). The Skarstrom cycle is normally employed as a reference to establish the feasibility of the PSA application to separate a given mixture.

The Skarstrom cycle is constituted by the following cyclic steps:

1. Feed: the $\mathrm{CH}_{4}-\mathrm{CO}_{2}$ mixture is fed to the fixed bed where the adsorbent is placed. Selective adsorption of $\mathrm{CO}_{2}$ takes place obtaining purified $\mathrm{CH}_{4}$ at the column product end at high pressure.

2. Blowdown: immediately before $\mathrm{CO}_{2}$ breaks through, the column should be regenerated. This is done by stopping the feed step and reducing the pressure of the column countercurrently to the feed step. Ideally, this step should be carried out until a new equilibrium state is established as shown in Figure 1. However, the blowdown step is stopped when the flowrate of $\mathrm{CO}_{2}$-rich stream exiting the column is small. With the reduction of pressure, $\mathrm{CO}_{2}$ is partially desorbed from the adsorbent. In this step, the lowest pressure of the system is achieved.

3. Purge: when the low pressure is achieved, the column will have $\mathrm{CO}_{2}$ molecules in the adsorbed phase but also in the gas phase. In order to reduce the amount of $\mathrm{CO}_{2}$ in both phases, a purge step is performed counter-current to feed step. In the purge, some of the purified methane is recycled (light recycle) to displace $\mathrm{CO}_{2}$ from the $\mathrm{CH}_{4}$ product end.

4. Pressurization: Since the purge is also performed at low pressure, in order to restart a new cycle, the pressure should be increased. Pressurization can be carried out cocurrently with the feed stream of counter-currently with purified $\mathrm{CH}_{4}$. The selection of the pressurization strategy is not trivial and may lead to very different results (Ahn et al., 1999).

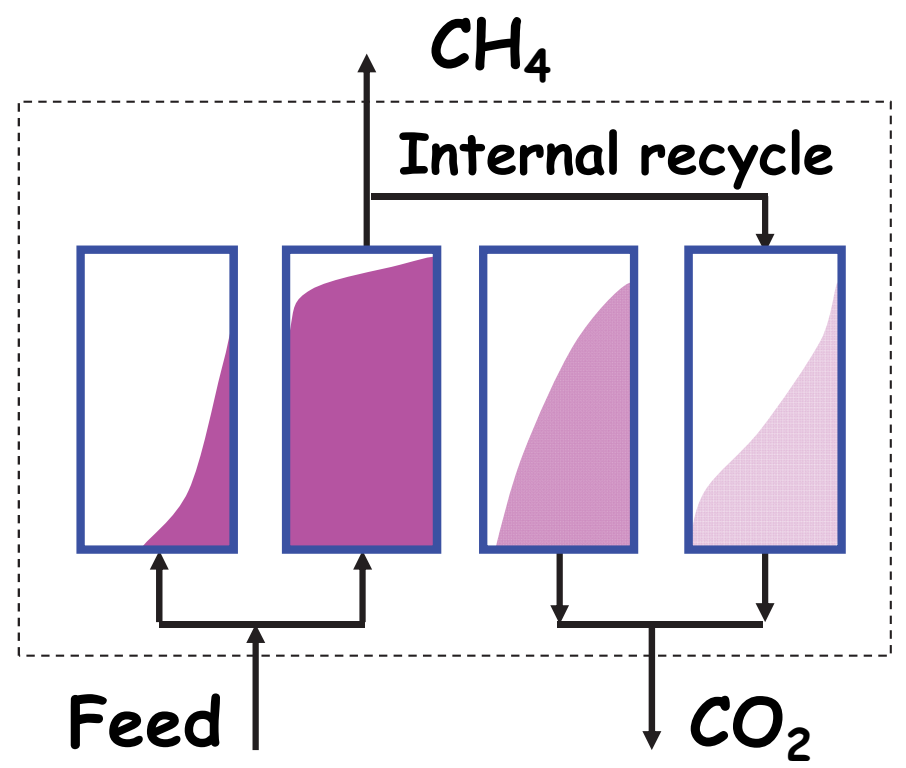

Fig. 6. Schematic representation of the different steps in a Skarstrom cycle. The dotted line represents the external boundary used to calculate performance parameters. 
A schematic representation of the different steps of one column in a single cycle is shown in Figure 6. Note that in this image an external boundary was established. This boundary is used to define the performance parameters of the PSA unit: $\mathrm{CH}_{4}$ purity, $\mathrm{CH}_{4}$ recovery and unit productivity. They are calculated using the following equations:

$$
\begin{gathered}
\text { PURITY }=\frac{\left.\int_{0}^{t f e e d} C_{C H 4} u\right|_{z=L} d t}{\left(\left.\int_{0}^{t f e e d} C_{C H 4} u\right|_{z=L} d t+\left.\int_{0}^{t f e e d} C_{C O 2} u\right|_{z=L} d t\right)} \\
\text { RECOVERY }=\frac{\left.\int_{0}^{t f e e d} C_{C H 4} u\right|_{z=L} d t-\left.\int_{0}^{t p u r g e} C_{C H 4} u\right|_{z=L} d t}{\left.\int_{0}^{t f e e d} C_{C H 4} u\right|_{z=0} d t+\left.\int_{0}^{t p r e s s} C_{C H 4} u\right|_{z=L} d t} \\
\text { PRODUCTIVITY }=\frac{\left(\left.\int_{0}^{t f f e d} C_{C H 4} u\right|_{z=L} d t-\left.\int_{0}^{t p u r g e} C_{C H 4} u\right|_{z=L} d t\right) \cdot A_{c o l}}{t_{c y c l e} w_{\text {ads }}}
\end{gathered}
$$

where $C_{\mathrm{CH} 4}$ is the concentration of methane, $u$ is the velocity, $t_{\text {cycle }}$ is the total cycle time, $A_{\text {col }}$ is the column area and $w_{\text {ads }}$ is the total adsorbent weight. Note that the calculation of $\mathrm{CH}_{4}$ recovery and unit productivity involves the molar flowrates of the different steps where some $\mathrm{CH}_{4}$ is recycled. In the case of changing the cycle configurations, the equations to calculate the process parameters may also be different.

In the cycle developed by Guerin-Domine, a pressure equalization step between different columns take place between feed and blowdown and after the purge and the pressurization. The pressure equalization steps are very advantageous for PSA applications since they help to improve the recovery of the light product, they reduce the amount of gas lost in the blowdown step and as a direct consequence, the purity of the $\mathrm{CO}_{2}$-rich stream obtained in the blowdown (and purge) steps increases and also less power is consumed if blowdown is carried out under vacuum. It should be mentioned that in the PSA process for biogas upgrading, it is important to perform some pressure equalization steps to reduce the amount of methane that is lost in the blowdown step. The amount of $\mathrm{CH}_{4}$ lost in the process is termed as $\mathrm{CH}_{4}$ slip and in PSA processes is around 3-12\% (Pettersson and Wellinger, 2009). More advanced cycles for other applications also make extensive use of the equalization steps: up to three pressure equalizations between different columns take place in $\mathrm{H}_{2}$ purification (Schell et al., 2009; Lopes et al., 2011). As an example, in Figure 7, the pressure history over one cycle is shown for the case of a two-column PSA process using a modified Skarstrom cycle with one pressure equalization step (Santos et al., 2011).

Continuing with the example of CMS-3K as selective adsorbent for biogas upgrading, the cyclic performance of a Skarstrom cycle is shown in Figure 8. In this example, the feed was a stream of $\mathrm{CH}_{4}(55 \%)-\mathrm{CO}_{2}(45 \%)$ resembling a landfill gas $(\mathrm{T}=306 \mathrm{~K})$, with a feed pressure of 3.2 bar. The blowdown pressure was established in 0.1 bar and pressurization step was carried out co-current with feed stream (Cavenati et al., 2005). Figure 8(a) shows the pressure history over one entire cycle while Figure $8(\mathrm{~b})$ shows the molar flowrate of each gas exiting the column. It can be seen that in the feed step, a purified stream of $\mathrm{CH}_{4}$ is obtained. In this experiment, the purity of $\mathrm{CH}_{4}$ was $97.1 \%$ with a total recovery of $79.4 \%$ 
(Cavenati et al., 2005). An important feature of the CMS-3K adsorbent is related to the very slow adsorption kinetics of $\mathrm{CH}_{4}$. In Figure 8(c) the simulated amount of $\mathrm{CH}_{4}$ adsorbed is shown. It can be observed that after reaching the cyclic steady state (CSS), the loading of $\mathrm{CH}_{4}$ per cycle is constant: this means that no $\mathrm{CH}_{4}$ is adsorbed in the column. This is very important since no $\mathrm{CH}_{4}$ will be adsorbed in the pressurization step, even with a very strong increase in its partial pressure. Unfortunately, the narrow pores also make $\mathrm{CO}_{2}$ adsorption (and desorption) difficult, reason why only part of the capacity of the bed is employed as shown in Figure 8(d) resulting in small unit productivity.
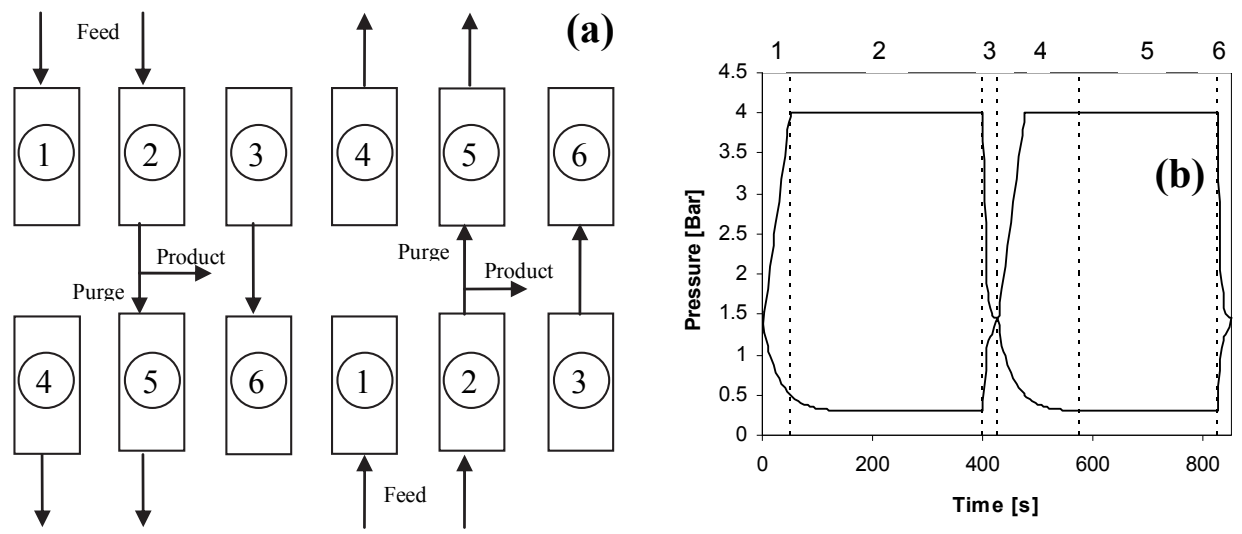

Fig. 7. Scheduling of a Skarstrom cycle in a two column PSA unit: (a) step arrangement: 1. Pressurization; 2. Feed; 3. Depressurization; 4. Blowdown; 5. Purge; 6. Equalization. (b) Pressure history of both columns during one cycle.

As can be seen, an important amount of $\mathrm{CH}_{4}$ is lost in the blowdown step, since there is no pressure equalization: pressure drops from 3.2 bar to 0.1 bar having at least $55 \%$ of $\mathrm{CH}_{4}$ in the gas phase. The main problem of using the Skarstrom cycle for biogas upgrading is that the $\mathrm{CH}_{4}$ slip is quite high. Since the Skarstrom cycle is potentially shorter than more complex cycles, the unit productivity is higher. Keeping this in mind, it may be interesting to employ this cycle in the case of combining the production of fuel (bio- $\left.\mathrm{CH}_{4}\right)$ and heat or electricity where the gas obtained from the blowdown step can be directly burned or blended with raw biogas.

In order to avoid large $\mathrm{CH}_{4}$ slip, at least, one pressure equalization should be employed to reduce the amount of methane in the gas phase that is lost in the blowdown stream. If such step is performed, it is possible to increase the methane recovery from $79.4 \%$ to $86.3 \%$ obtaining methane with a similar purity $(97.1 \%)$. It can be concluded that the increase of number of equalization steps will reduce the methane lost in the blowdown step. Furthermore, if less gas is present in the column when the blowdown step starts, the vacuum pump will consume less power. However, to perform multiple pressure equalizations, the number of columns and the complexity of operation of the unit increase. Furthermore, the time required by the multiple pressure equalization steps will reduce the unit productivity resulting in larger units. A trade-off situation is normally achieved in PSA units with four-columns employing up to two pressure equalization steps before blowdown (Wellinger, 2009). 
Another source of $\mathrm{CH}_{4}$ slip is the exit stream of the purge step: in the purge, part of the purified $\mathrm{CH}_{4}$ stream is recycled (counter-currently) to clean the remaining $\mathrm{CO}_{2}$ in the column. Since $\mathrm{CH}_{4}$ is not adsorbed, after a short time it will break through the column. However, if the purge step is too short, the performance of the PSA cycle is poor. In order to achieve very small $\mathrm{CH}_{4}$ slip keeping an efficient purge, one possible solution is to recompress and recycle this stream (Dolan and Mitariten, 2003). Furthermore, if this stream is recycled, the flowrate of the purge can be used to control the performance of the PSA cycle when strong variations of the biogas stream take place $\left(\mathrm{CO}_{2}\right.$ content or total flowrate).
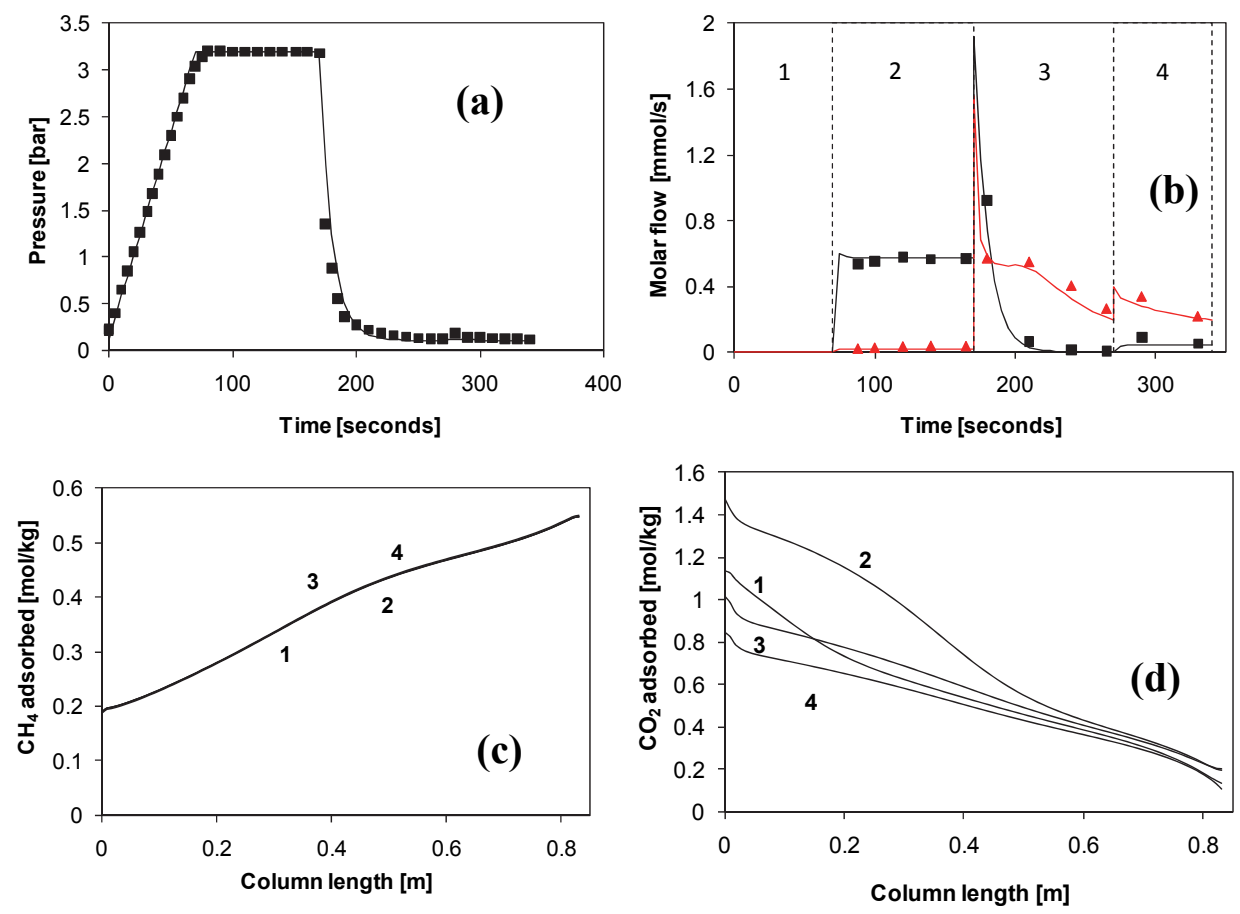

Fig. 8. PSA separation of a mixture of $\mathrm{CH}_{4}(55 \%)-\mathrm{CO}_{2}(45 \%)$ using a packed bed filled with CMS-3K operating with a Skarstrom cycle (1. Pressurization; 2. Feed; 3. Blowdown; 4. Purge). Feed pressure: 3.2 bar; blowdown pressure: 0.1 bar. (a) Pressure history over one cycle; (b) molar flowrate exiting the column; (c) loading of $\mathrm{CH}_{4}$ at the end of each step; loading of $\mathrm{CO}_{2}$ at the end of each step. Data from Cavenati et al., 2005.

\section{New markets and improvements of PSA technology}

As mentioned before, the biogas market has enormous possibilities to grow. One of the most important sectors that may trigger large growth of PSA development is within small farms. In such cases, the biogas can be employed for heating and to generate electricity, but a portion of the stream (or the exceeding) can be upgraded to fuel. In such applications, besides the specifications of process performance, six characteristics are desired for any upgrading technology: 
1. Economic for small streams,

2. Compact,

3. Automated,

4. Minimal attendance (by non-expert person most of the time),

5. Possible to switch on / off quite fast

6. Deliver product specifications even when subjected to strong variations in feed.

The PSA technology can potentially be employed in such applications since it can satisfy most of the criteria established above. As an example it can be mentioned that some plants of the Molecular Gate technology are operated remotely (automated with minimal attendance) transported in trucks (compact) and they are employed for small streams of natural gas (Molecular Gate, 2011). However, the scale of small biogas application is quite small (smaller than $10 \mathrm{~m}^{3}$ /hour). Furthermore, fast switch on/off a PSA unit for several times was not reported in literature and surely require dedicated research as well as PSA design to handle strong variations in feed streams.

The two major areas where research should be conducted to deliver a PSA unit to tackle such applications are: new adsorbents and design engineering.

\subsection{New adsorbents}

Despite of the explosion in discovery of new materials with a wide range of possibilities, most of the PSA units existing in the market still use the well-known zeolites $4 \mathrm{~A}, 5 \mathrm{~A}$ and 13X), activated carbons, carbon molecular sieves, silica gel and alumina. Since the adsorbent material is the most important choice for the design of the PSA unit, more efficient materials should be employed to satisfy more market constrains (energy consumption and size). One interesting example of the possibility of application of new materials is the Molecular Gate technology, where the utilization of narrow pore titanosilicates (ETS-4) lead to a successful technology for $\mathrm{CH}_{4}$ upgrading (Kuznicki, 1990; Dolan and Mitariten, 2003). The ETS-4 materials when partially exchanged with alkali-earth metals present a unique property of pore contraction when increasing the temperature of activation (Marathe et al., 2004; Cavenati et al., 2009). This property is very important since the pores can be adjusted with a very high precision to do separations as complex as $\mathrm{CH}_{4}-\mathrm{N}_{2}$. Within this kind of inorganic substrates, other interesting material that deserves attention are the aluminophosphates. Even when these materials do not present a very high $\mathrm{CO}_{2}$ capacity, they have quite linear isotherms (ideal for utilization in PSA applications) and also some of them present Type $\mathrm{V}$ isotherms for water adsorption, which means that they have certain tolerance (and regenerability) if traces of water are present (Liu et al., 2011).

In the last years, a new family of materials with extremely high surface area has been discovered (Li et al., 1999; Wang et al., 2002; Millward and Yaghi, 2005; Mueller et al., 2005; Kongshaug et al., 2007). The metal-organic frameworks (MOFs) can actually adsorb extremely large amounts of $\mathrm{CO}_{2}$ when compared with classical adsorbents. Furthermore, it is possible to adjust the structure in such a way that the steepness of the isotherm is mild and thus regeneration is simpler. An example of this high $\mathrm{CO}_{2}$ loading on MOFs is given in Figure 9 where the isotherms of $\mathrm{CO}_{2}$ and $\mathrm{CH}_{4}$ on $\mathrm{Cu}-\mathrm{BTC}$ are shown at different temperatures (Cavenati et al., 2008). Comparing these isotherms with the ones presented by zeolite 13X (Figure 3), it can be observed that the steepness of the isotherm is quite mild leading to much higher "cyclic capacity" than zeolite 13X. Several MOFs were studied to separate $\mathrm{CH}_{4}-\mathrm{CO}_{2}$ mixtures (Schubert et al., 2007; Cavenati et al., 2008; Llewellyn et al., 2008; Dietzel et al., 2009; Boutin et al., 2010). Most of them present excellent properties for $\mathrm{CO}_{2}$ 
adsorption, eventually with mild-non-linearity of $\mathrm{CO}_{2}$ isotherms. Issues to commercialize these materials are related to the correct formulation and final shaping without significantly loosing their surface area.
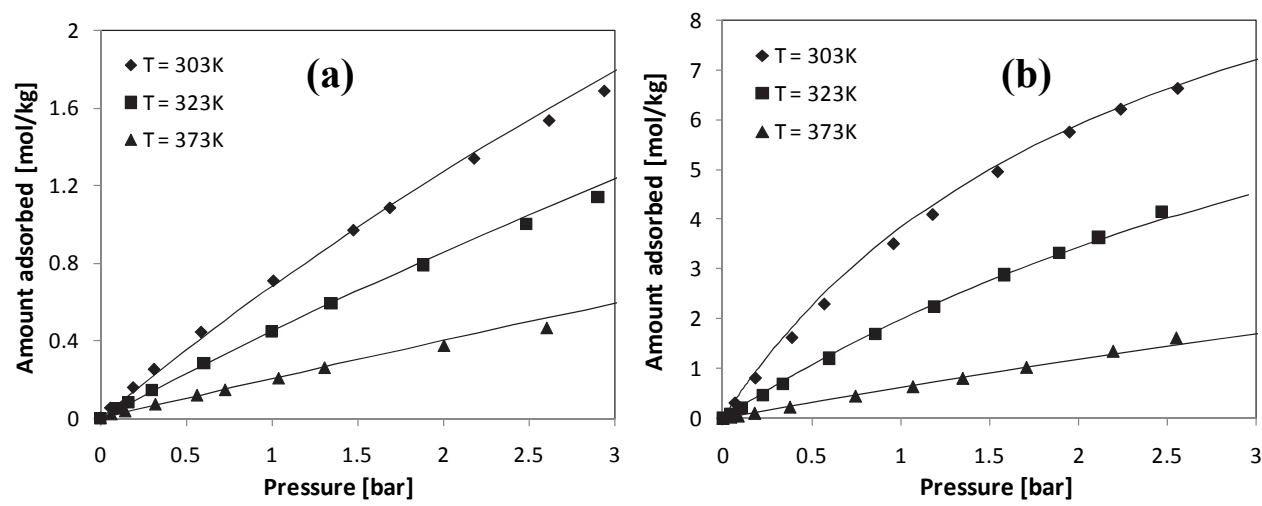

Fig. 9. Adsorption equilibrium of $\mathrm{CO}_{2}$ (a) and $\mathrm{CH}_{4}$ (b) on $\mathrm{Cu}-\mathrm{BTC} \mathrm{MOF}$ at 303,323 and $373 \mathrm{~K}$ (data from Cavenati et al., 2008).

The extremely high $\mathrm{CO}_{2}$ loading of MOFs indicate that the size of the PSA unit can be significantly reduced using this material instead of classical adsorbents. Furthermore, the $\mathrm{CO}_{2}$ adsorption kinetics in several MOFs is quite fast, thus most of its loading can actually be employed per cycle. One of the main issues with MOFs is that water cannot be present in the system and should be removed in a previous step (which should not be an important problem since water must be removed anyway).

\subsection{Alternative PSA design}

A possible route to design a new PSA unit involve the selection of the adsorbent, the selection of the PSA cycle that should be used, the sizing of the unit, the definition of operating variables for efficient adsorbent regeneration and finally the arrangement of the multi-column process for continuous operation (Knaebel and Reinhold, 2003). However, in the development of new applications in small scale, other parameters can be considered, particularly the ones related to the design of the unit. One example of the possibility of outof-the-box process design is the rotary valve employed by Xebec that has allowed the industrial application of rapid-PSA units for biogas upgrading (Toreja et al., 2011). When designing small units, the shape of the columns can be different to the traditional ones and this fact can be used to maximize the ratio of adsorbent employed per unit volume. Furthermore, in some cases of high $\mathrm{CO}_{2}$ contents, the heat of adsorption may increase the temperature of the adsorbent in such a way that the effective capacity decreases significantly. In such cases, the possibility of effective heat exchange with the surroundings can be an alternative (Bonnissel et al., 2001) as well as increase the heat capacity of the column (Yang, 1987). Other alternative to increase the unit productivity when using kinetic adsorbents (like CMS-3K) is to use a second layer of adsorbent with larger pores (fast adsorption) and with easy regenerability (Grande et al., 2008). By using this layered arrangement, it is possible to "trap" the $\mathrm{CO}_{2}$ in the final layer for some additional time, which is enough to double the unit productivity of the system (keeping similar $\mathrm{CH}_{4}$ purity 
and recovery). This layering of adsorbents can also be employed to remove water and $\mathrm{CO}_{2}$ in the same bed as it is being done in other $\mathrm{CO}_{2}$ applications ( $\mathrm{Li}$ et al., 2008).

Perhaps the most important engineering challenges of new PSA design are related to the modification of the PSA cycles. Most of the PSA units existing in industry nowadays use the Skarstrom cycle (or small variations of it) with several pressure equalizations to reduce the $\mathrm{CH}_{4}$ slip. The utilization of different cycles can be adjusted for different applications of the biogas stream: production of extremely high $\mathrm{CH}_{4}$ purity, small $\mathrm{CH}_{4}$ slip, combined heat / electricity and/or fuel generation, etc. The possibility of "playing" with the step arrangement in a PSA cycle for a given application is virtually infinite. Extreme variations in PSA cycles can be achieved with PSA units with three or four columns. An example of such possibilities is given in Figure 10 where a different cycle is presented in order to radically improve the unit productivity of kinetic adsorbents (Santos et al., 2011b). This 4-column PSA cycle was designed keeping in mind that the adsorption should be continuous, that at least one equalization step is necessary to reduce $\mathrm{CH}_{4}$ slip and also to improve the contact time between gas and solid which is particularly important to increase the loading of $\mathrm{CO}_{2}$ in the adsorbent. To enhance the contact time between the adsorbent and the feed stream, a leadtrim concept is employed (Keller et al., 1987).

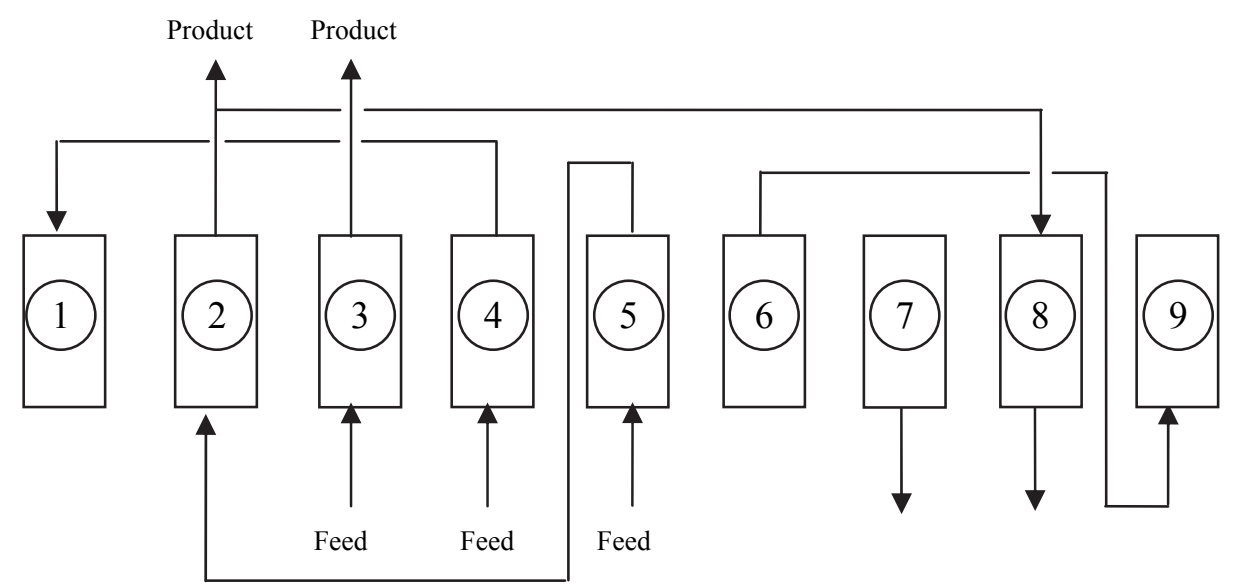

Fig. 10. Scheduling of a column for a PSA cycle for biogas upgrading using lead-trim concept. The steps are: 1 . Pressurization; 2. Trim feed; 3-4. Feed; 5. Lead adsorption; 6. Depressurization; 7. Blowdown; 8. Purge; 9. Pressure equalization.

In a kinetic adsorbent, the $\mathrm{CO}_{2}$ breakthrough happens relatively fast and the mass transfer zone is quite large as shown in Figure 8(d). In order to avoid contamination of the $\mathrm{CH}_{4}$-rich stream, the feed step is normally stopped, but using the lead-trim cycle arrangement, the gas exiting one column is routed to a second column where this residual $\mathrm{CO}_{2}$ can be adsorbed, giving the first column extra time to adsorb $\mathrm{CO}_{2}$. This column arrangement leads to a column with virtually the double of the size (only for some adsorption steps). Also, the column that is ready for regeneration has a higher content of $\mathrm{CO}_{2}$, which also result in small $\mathrm{CH}_{4}$ slip. A simulation of the performance of this PSA cycle using CMS-3K is shown in Figure 11. Using this column arrangement, $\mathrm{CH}_{4}$ purity of $98.3 \%$ could be obtained with a total recovery of $88.5 \%$ and a unit productivity of 5.5 moles of $\mathrm{CH}_{4}$ per hour per kilogram of 
adsorbent (Santos et al., 2011b). From the $11.5 \%$ of $\mathrm{CH}_{4}$ lost in blowdown and purge steps, around $7 \%$ is lost in the purge step, which means that if this stream is recycled, the $\mathrm{CH}_{4}$-slip will drop to values lower than $5 \%$. Note that in Figure $11(\mathrm{~b}), \mathrm{CO}_{2}$ started to break through the column at the end of the feed step. In this case the objective was to produce $\mathrm{CH}_{4}$ with purity higher than $98 \%$, but this cycle can be regulated if higher purity is required. Furthermore, the cycle is quite efficient and it does not require going to 0.1 bar for regeneration and only 0.3 bar are employed, which significantly reduced the power consumption when compared to classical step arrangements.
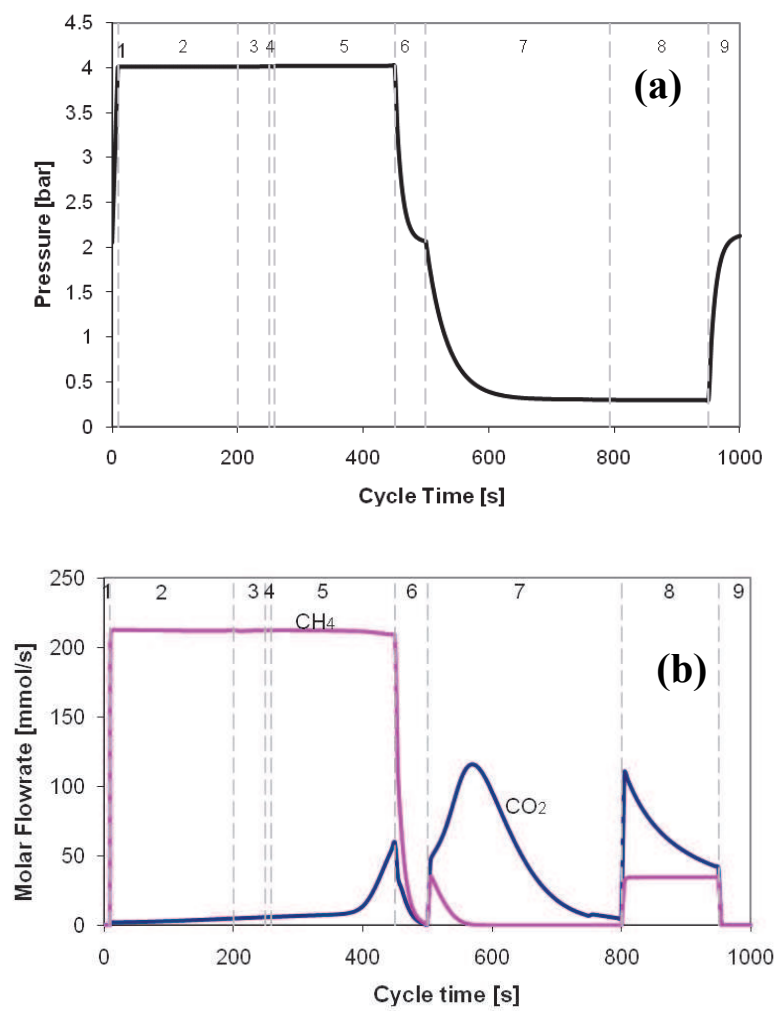

Fig. 11. Simulation of a 4-column PSA process using the lead-trim cycle (see Figure 10) with CMS-3K for separation of a mixture of $\mathrm{CH}_{4}(67 \%)$ and $\mathrm{CO}_{2}(33 \%)$. (a) pressure history of one cycle; (b) molar flow of $\mathrm{CH}_{4}$ and $\mathrm{CO}_{2}$ after cyclic steady state was achieved. Feed pressure: 4 bar; Blowdown pressure: 0.3 bar; Temperature: 323 K.Data from Santos et al., 2011b.

\section{Conclusions}

Pressure Swing Adsorption (PSA) has already proved that it is an efficient technology for biogas upgrading under different operating conditions. This work presents a summary of the available technologies for biogas upgrading (water and chemical scrubbing and membranes) and gives a special focus to PSA technology. A brief overview of the operating principles of PSA technology is given, with some insights in the adsorbents employed and 
the design possibilities of the PSA units. A final section shows some of the new range of possibilities to improve its design for new applications, oriented to small biogas flowrates encountered in farms. Certainly, there is still much research required to successfully develop PSA technology for small flowrates applications. Certainly, a strong link between materials science and process engineering can contribute to develop this technology faster. Successful application of PSA in such market should expand the application of biogas utilization as environmentally-friendly and sustainable fuel.

\section{Acknowledgments}

The author would like to acknowledge Prof. Alirio E. Rodrigues for its constant guidance in adsorption science along several years. The assistance of many former colleagues of the Laboratory of Separation and Reaction Engineering at the University of Porto was also essential in developing most of the research activities reported in this work. Also, I would like to express my gratitude to the support of SINTEF Materials and Chemistry, particularly to Dr. Richard Blom, in writing this Chapter.

\section{References}

Ahn, H.; Lee, C-H; Seo, B.; Yang, J.; Baek, K (1999). Backfill Cycle of a Layered Bed H2 PSA Process. Adsorption, Vol. 5, No. 4, (October 1999), pp 419-433, ISSN 0929-5607.

Air Liquide (2011). Biogas Recovery System. 02.04.2011. Available at: http://www.dta.airliquide.com/en/our-offer/decentralized-energies/biogas.html

Basmadjian, D. (1997). The Little Adsorption Book: A Practical Guide for Engineers and Scientists; CRC Press, 1997.

Bonnissel, M.P.; Luo, L.; Tondeur, D (2001). Rapid Thermal Swing Adsorption. Ind. Eng. Chem. Res. Vol. 40, No. 10, (April 2001), pp 2322-2334, ISSN 0888-5885.

Boutin, A.; Coudert, F-X.; Springuel-Huet, M-A.; Neimark, A.V.; Ferey, G.; Fuchs, A.H (2010). The Behavior of Flexible MIL-53 (Al) upon $\mathrm{CH}_{4}$ and $\mathrm{CO}_{2}$ Adsorption. J. Phys Chem. C. Vol. 114, No. 50, (December 2010), pp 22237-22244, ISSN 1932-7447.

Cavenati, S.; Grande, C.A.; Rodrigues, A.E (2004). Adsorption Equilibrium of Methane, Carbon Dioxide and Nitrogen on Zeolite 13X at High Pressures. J. Chem. Eng. Data, Vol. 49, No. 4, (June 2004), pp 1095-1101, ISSN 0021-9568.

Cavenati, S.; Grande, C.A.; Rodrigues, A.E (2005). Upgrade of Methane from Landfill Gas by Pressure Swing Adsorption. Energy \& Fuels, Vol. 19, No. 6, (August 2005), pp 25452555, ISSN 0887-0624.

Cavenati, S.; Grande, C.A.; Rodrigues, A.E (2006). Removal of Carbon Dioxide from Natural Gas by Vacuum Pressure Swing Adsorption. Energy \& Fuels, Vol. 20, No. 6, (September 2006), pp 2648-2659, ISSN 0887-0624.

Cavenati, S.; Grande, C.A.; Rodrigues, A.E (2008). Metal Organic Framework Adsorbent for Biogas Upgrading. Ind. Eng. Chem. Res. Vol. 47, No. 16, (July 2008), pp 6333-6335, ISSN 0888-5885.

Cavenati, S.; Grande, C.A.; Lopes, F.V.S.; Rodrigues, A.E (2009). Adsorption of Small Molecules on Alkali-Earth Modified Titanosilicates. Microp. Mesop. Mater, Vol. 121, No. 1-3, (May 2009), pp 114-120, ISSN 1387-1811.

Da Silva, F. A. Cyclic Adsorption Processes: Application to Propane/Propylene Separation. Ph.D. Dissertation, University of Porto, Portugal, 1999. 
Dietzel, P.D.C.; Besikiotis, B.; Blom, R (2009). Application of Metal-Organic Frameworks with Coordinatively Unsaturated Metal Sites in Storage and Separation of Methane and Carbon Dioxide. J. Mater. Chem. Vol. 19, (August 2009), pp 7362-7370, ISSN 0959-9428.

Demirbas, M.F.; Balat, M.; Balat, H (2011). Biowastes-to-biofuels. Energy Conv. Management, Vol.52, No. 4, (April 2011), pp 1815-1828, ISSN 0196-8904.

Dolan, W.B.; Mitariten, M.J (2003). $\mathrm{CO}_{2}$ Rejection from Natural Gas. United States Patent US 2003/0047071, 2003.

Gavala, H.N.; Yenal, U.; Skiadas, I.V.; Westermann, P.; Ahring, B.K. (2003). Mesophilic and Thermophilic Anaerobic Digestion of Primary and Secondary Sludge. Effect of Pretreatment at Elevated Temperature. Water Research. Vol. 37, No. 19, (November 2003), pp 4561-4572, ISSN 0043-1354.

Grande, C.A.; Rodrigues, A.E (2007). Biogas to Fuel by Vacuum Pressure Swing Adsorption I. Behavior of Equilibrium and Kinetic-Based Adsorbents. Ind. Eng. Chem. Res., Vol. 46, No. 13, (May 2007), pp 4595-4605, ISSN 0888-5885.

Grande, C.A.; Cavenati, S.; Rodrigues, A.E (2008). Separation Column and Pressure Swing Adsorption Process for Gas Purification. World Patent Application WO/2008/072215.

Guerin de Montgareuil, P.; Domine, D. Process for Separating a Binary Gaseous Mixture by Adsorption. US Patent 3,155,468, 1964.

Keller, G.E.; Anderson, R.A.; Yon, C.M (1987). Handbook of Separation Process Technology. JohnWiley, New York.

Knaebel, K.S.; Reinhold, H. E (2003). Landfill Gas: From Rubbish to Resource. Adsorption Vol. 9, No. 1, (March 2003), pp 87-94, ISSN 0929-5607.

Kongshaug, K.O.; Heyn, R.H.; Fjellvag, H.; Blom, R (2007). MOF-compounds as Gas Adsorbers. World Patent WO/2007/128994, 2007.

Kuznicki, S.M. (1990). Preparation of Small-Pored Crystalline Titanium Molecular Sieve Zeolites. U.S. Patent 4,938,939. July 1990.

Llewellyn, P.L.; Bourrelly, S.; Serre, C.; Vimont, A.; Daturi, M.; Hamon, L.; De Weireld, G.; Chang, J-S; Hong, D-Y; Hwang, Y.K.; Jhung, S.W.; Ferey, G (2008). High Uptakes of $\mathrm{CO} 2$ and CH4 in Mesoporous Metal-Organic Frameworks MIL-100 and MIL-101. Langmuir, Vol. 24, No. 14, (July 2008), pp 7245-7250, ISSN 0743-7463.

Li, G.; Xiao, P.; Webley, P.; Zhang, J.; Singh, R.; Marshall, M. (2008). Capture of $\mathrm{CO}_{2}$ from High Humidity Flue Gas by Vacuum Swing Adsorption with Zeolite $13 \mathrm{X}$. Adsorption, Vol. 14, No. 2-3, (June 2008), pp 415-422, ISSN 0929-5607.

Li, H.; Eddaoudi, M. O'Keeffe, O. M. Yaghi (1999). Design and Synthesis of an Exceptionally Stable and Highly Porous Metal-Organic Framework. Nature, Vol. 402, (November 1999), pp 276-279, ISSN 0028-0836.

Liu, Q.; Cheung, N.C.O.; Garcia-Bennet, A.E.; Hedin, N (2011). Aluminophosphates for CO2 Separation. ChemSUSChem, Vol. 4, No. 1, (January 2011), pp 91-97, ISSN 1864-5631.

Lopes, F.V.S.; Grande, C.A.; Rodrigues, A.E. (2011). Activated Carbon for Hydrogen Purification by Pressure Swing Adsorption. Multicomponent Breakthrough Curves and PSA Performance. Chem. Eng. Sci., Vol. 66, No. 3, (February 2011), pp 303-317, ISSN 0009-2509.

Marathe, R.P.; Mantri, K.; Srinivasan, M.P.; Farooq, S. (2004). Effect of Ion Exchange and Dehydration Temperature on the Adsorption and Diffusion of Gases in ETS-4. Ind. Eng. Chem. Res., Vol. 43, No. 17, (July 2004), pp 5281-5290, ISSN 0888-5885. 
Millward, A.R.; Yaghi, O.M (2005). Metal-organic Frameworks with Exceptionally High Capacity for Storage of Carbon Dioxide at Room Temperature. J. Am. Chem. Soc. Vol. 127, No. 51, (December 2005), pp 17998-17999, ISSN 0002-7863.

Molecular Gate Adsorption Technology. 02.04.2011. Available at: www.moleculargate.com/molecular-gate-CO2-removal-nitrogen-rejection.html.

Monteiro, E.; Mantha, V.; Rouboa, A. (2011). Prospective Application of Farm Cattle Manure for Bioenergy Production in Portugal. Renewable Energy. Vol. 36, No. 2, (February 2011), pp 627-631, ISSN 0960-1481.

Mueller, U.; Lobree, L.; Hesse, M.; Yaghi, O.; Eddaoudi, M (2005). Shaped Bodies Containing Metal-Organic Frameworks. U. S. Patent 6,893,564, 2005.

Pettersson, A.; Wellinger, A (2009). Biogas Upgrading Technologies - Developments and Innovation, 02.04.2011. Available at: http://www.iea-biogas.net/

Ruthven, D.M. (1984) Principles of Adsorption and Adsorption Processes; John Wiley \& Sons: New York.

Ruthven, D. M.; Farooq, S.; Knaebel, K. S. (1994) Pressure Swing Adsorption; Wiley-VCH, New York, 1994. ISBN: 0471188182.

Santos, M.P.S.; Grande, C.A.; Rodrigues, A.E (2011). Pressure Swing Adsorption for Biogas Upgrading. Effect of Recycling Streams in PSA Design. Ind. Eng. Chem. Res., Vol. 50, No. 2, (December 2010), pp 974-985, ISSN 0888-5885.

Santos, M.P.S.; Grande, C.A.; Rodrigues, A.E (2011b).New Cycle Configuration to Enhance Performance of Kinetic PSA Processes. Chem. Eng. Sci., Vol. 66, No. 8, (April 2011), pp 1590-1599, ISSN 0009-2509.

Schell, J.; Casas, N; Mazzotti, M (2009). Pre-Combustion $\mathrm{CO}_{2}$ Capture for IGCC Plants by an Adsorption Process. Energy Procedia, Vol. 1, No. 1, (February 2009), pp 655-660, ISSN 1876-6102.

Schubert M.; Müller, U.; Hesse, M.; Diehlmann, U (2007). Process for Preparing Porous Metal-Organic Framework Materials. World Patent WO/2007/090809.

Skarstrom, C. W. Method and apparatus for fractionating gaseous mixtures by adsorption. U.S. Patent No. 2944 627; 1960

Srinivasan, R.; Auvil, S.R.; Schork, J.M (1995) mass Transfer in Carbon Molecular Sieves- an Interpretation of Langmuir Kinetics. Chem. Eng. J. Vol. 57, No. 2, (April 1995), pp 137-144, ISSN 0923-0467.

Toreja, J.; VanNostrand, B.; Chan, N.; Dickinson, J.P (2011). Rotary-Valve, Fast-Cycle Pressure-Swing Adsorption Technology Allows West Coast Platform to Meet Tight California Specifications and Recover Stranded Gas. Laurence Reid Gas Conditioning Conference. 02.04.2011.Available at: www.xebecinc.com/pdf/RotaryValve-Fast-Cycle-Pressure-Swing-Adsorption-Paper.pdf

Wang, Q.M.; Shen, D.; Bülow, M.; Lau, M.L.; Deng, S.; Fitch, F.R.; Lemcoff, N.O.; Semanscin, J (2002). Metallo-organic Molecular Sieve for Gas Separation and Purification. Microp. Mesop. Mater, Vol. 55, No. 2, (September 2002), pp 217-230, ISSN 1387-1811.

Wellinger, A (2009). Gas Upgrading Issues. European Biomethane Fuel Conference. Göteborg, Sweden, September 2009. Available at: http://www.biogasmax.eu/european-conference-on-biomethane/download/

Yang, R. T (1987) . Gas Separation by Adsorption Processes Butterworths: Boston, 1987. ISBN: 0409900044. 


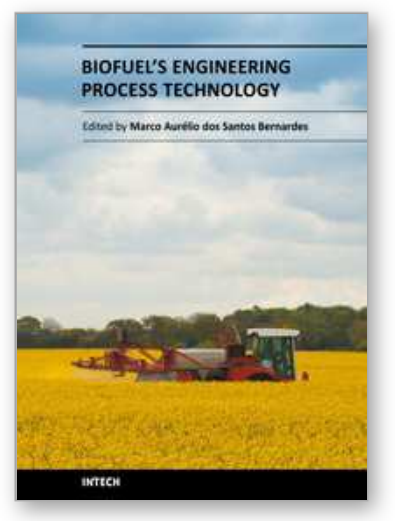

\author{
Biofuel's Engineering Process Technology \\ Edited by Dr. Marco Aurelio Dos Santos Bernardes
}

ISBN 978-953-307-480-1

Hard cover, 742 pages

Publisher InTech

Published online 01, August, 2011

Published in print edition August, 2011

This book aspires to be a comprehensive summary of current biofuels issues and thereby contribute to the understanding of this important topic. Readers will find themes including biofuels development efforts, their implications for the food industry, current and future biofuels crops, the successful Brazilian ethanol program, insights of the first, second, third and fourth biofuel generations, advanced biofuel production techniques, related waste treatment, emissions and environmental impacts, water consumption, produced allergens and toxins. Additionally, the biofuel policy discussion is expected to be continuing in the foreseeable future and the reading of the biofuels features dealt with in this book, are recommended for anyone interested in understanding this diverse and developing theme.

\title{
How to reference
}

In order to correctly reference this scholarly work, feel free to copy and paste the following:

Carlos A. Grande (2011). Biogas Upgrading by Pressure Swing Adsorption, Biofuel's Engineering Process Technology, Dr. Marco Aurelio Dos Santos Bernardes (Ed.), ISBN: 978-953-307-480-1, InTech, Available from: http://www.intechopen.com/books/biofuel-s-engineering-process-technology/biogas-upgrading-bypressure-swing-adsorption

\section{INTECH}

open science | open minds

\section{InTech Europe}

University Campus STeP Ri Slavka Krautzeka 83/A

51000 Rijeka, Croatia Phone: +385 (51) 770447

Fax: +385 (51) 686166

www.intechopen.com

\section{InTech China}

Unit 405, Office Block, Hotel Equatorial Shanghai

No.65, Yan An Road (West), Shanghai, 200040, China

中国上海市延安西路65号上海国际贵都大饭店办公楼 405 单元

Phone: +86-21-62489820

Fax: +86-21-62489821 
(C) 2011 The Author(s). Licensee IntechOpen. This chapter is distributed under the terms of the Creative Commons Attribution-NonCommercialShareAlike-3.0 License, which permits use, distribution and reproduction for non-commercial purposes, provided the original is properly cited and derivative works building on this content are distributed under the same license. 